\title{
VOLUME 13, NUMBER 2
}

Rhonda Anderson is an Environmental Justice Organizer based at the Sierra Club's Detroit Office. She works actively with Detroit residents and local policy and decision makers to advocate for residents of communities which are overburdened with the cumulative effects of air pollutants and social and economic risks.

Karida L. Brown is Assistant Professor in the Department of Sociology at UCLA, specializing in the subfields of cultural sociology, race, and migration. Her research focuses on the relationship between macro structural transformations and the racial self. Her current project reconstructs the life histories of a cohort of African Americans who migrated throughout the Appalachian region during the twentieth century Great Migration.

Jennifer Carrera is Assistant Professor of Sociology and Environmental Science and Policy at Michigan State University. She received a PhD in sociology and an MS in environmental engineering from the University of Illinois in 2014. In 2014-2015 she completed a postdoctoral program in the Social Science Environmental Health Research Institute at Northeastern University under Phil Brown. Her current work uses citizen science and community-based participatory research (CBPR) methods to explore access to affordable and clean water in low-income and minority communities. Her projects include water quality affordability and shutoffs in Detroit, Michigan; failing septic systems in Lowndes County, Alabama; and the relationship between the politics of water governance and health in Flint, Michigan. Dr. Carrera's work aims to articulate everyday practices that produce and reproduce environmental injustices.

Kyle Crowder is the Blumstein-Jordan Professor of Sociology at the University of Washington. His research focuses on the causes and consequences of residential segregation by race and economic status, processes of residential mobility, and the effects of physical and social context on health and individual life conditions.

LeConté J. Dill is Assistant Professor in the Department of Community Health Sciences at the SUNY Downstate School of Public Health. She received her BA in Sociology from Spelman College, her MPH in Community Health Sciences from UCLA, her Doctor of Public Health degree from UC Berkeley, and was a Health Policy Postdoctoral Fellow in the Satcher Health Leadership Institute at Morehouse School of Medicine. As a community-engaged qualitative researcher, she examines the relationship between adolescent development and processes of the built environment, such as gentrification, foreclosures, and violence. Her recent work explores the

Du Bois Review, 13:2 (2016) 427-434.

(C) 2016 Hutchins Center for African and African American Research 1742-058X/16 \$15.00

doi:10.1017/S1742058X16000266 
multiple experiences of violence, coping, and resistance among urban girls of color. Ever interdisciplinary, Dr. Dill also writes and teaches poetry.

Mercedez Dunn is a PhD student in the Department of Sociology at the University of Michigan. She earned a BA in Sociology from Spelman College in 2013 and a MPH in Health Behavior and Health Education from the University of Michigan in 2016. Mercedez's current research explores how Black women navigate sexual interactions and sexual health risks in the context of Historically Black Colleges and Universities.

Dana R. Fisher is Professor of Sociology and the Director of the Program for Society and the Environment at the University of Maryland. Her research focuses on understanding the relationship between environmentalism and democracy-most recently focusing on environmental stewardship and American climate politics. This research employs a mix of quantitative and qualitative methods. Her current work analyzes data collected from environmental activists, stewardship organizations, volunteer stewards, students in the DC school system, as well as political elites involved in climate policymaking in the United States. In addition to her five books, she has also published her work in numerous peer-reviewed journals. For more information, see www.drfisher. umd.edu.

Carley Fisher-Maltese is an upper elementary Montessori teacher in Arlington Public Schools in VA and teaches as an adjunct faculty member at George Mason University in the Early Childhood Education Department. She completed her $\mathrm{PhD}$ at Rutgers, The State University of New Jersey. Her research focuses on science learning and the link between learning in informal and formal settings. She is particularly interested in outdoor learning spaces, such as school gardens and farms. Carley also has her Masters in Elementary Education from Teachers College, Columbia University and Elementary I \& II credential from the American Montessori Society. She has seven years of private and public elementary school teaching experience. She has always been very involved in the school gardens where she taught. She has written garden-, as well as standards-based, curriculum and trained teachers how to use the garden as a teaching tool. In addition, she is a member of the VA Farm-to-School Network. She is a strong advocate of farm-to-school programs and making nutritious, local food and experiential learning opportunities more accessible and prevalent in schools.

Jennifer J. García, PhD, MPH is a Lecturer in the Department of Health Sciences at California State University, Dominguez Hills, where she teaches about race, ethnicity, culture, and health. Her research interests focus on the social and contextual factors that create urban inequality and contribute to health disparities.

Stephen P. Gasteyer is Associate Professor of Sociology at Michigan State University. Dr. Gasteyer's research focuses on community development, environmental justice, and the political ecology of landscape change, with specific attention food, energy, water, and public health. Recent research has addressed the food access and impacts urban greening in small U.S. cities, alternative energy and community action, environmental equity in access to water and sanitation, and water governance. Dr. Gasteyer was a 2015-16 Fulbright Scholar at Birzeit University, Ramallah, Palestinian territories. He has authored or co-authored: twenty-five peer review publications; five book chapters; twenty-eight monographs, reports, and non-refereed articles. He co-authored two books in 2015: Rural Communities: Legacies and Change, 5th Edition; and Community Effects of Leadership Development Education: Citizen Empowerment for Civic Engagement. 
Gilbert C. Gee, PhD, is Professor of Community Health Sciences at UCLA. His research focuses on the social determinants of health inequities. His research has been honored with a group Merit Award from the National Institutes of Health for the development of a multicultural measure of discrimination for health surveys. He has also received two Scientific and Technical Achievement Awards from the Environmental Protection Agency for development of the Stress-Exposure-Disease Framework (in collaboration with Devon Payne-Sturges). Dr. Gee is currently the Editor of the Fournal of Health and Social Behavior.

Anjum Hajat is Research Assistant Professor of Epidemiology at the University of Washington, School of Public Health. Her research focuses on how stress, broadly defined, impacts health. Specifically she has been studying the impact of both psychosocial stressors and air pollution on cardiovascular and other health outcomes.

Mae Hardebeck is an undergraduate student at Dartmouth College, with passions in both sociology and quantitative social science. Her research interests lie in racial and ethnic studies, a result of her work experience at the Department of Justice Civil Rights Division and gaining exposure to law regarding language access and Title VI issues. In the future, she hopes to use data to help solve social problems. This is her first published work.

Barbara A. Israel is Professor in the Department of Health Behavior and Health Education, University of Michigan School of Public Health. Israel is widely acknowledged for her leadership in the use of community-based participatory research (CBPR) approaches in public health, and her longstanding work to address social determinants of health inequities, with a particular focus on Detroit, MI. She is actively involved in CBPR partnerships examining and addressing, for example, environmental triggers of childhood asthma, social and physical environmental determinants of cardiovascular disease, translation of research findings into policy change, and capacity building for CBPR. Israel is the recipient of numerous awards recognizing her public health leadership, including the Tom Bruce Award from the Community Based Public Health Caucus of the American Public Health Association.

Malia F. Jones, MPH, PhD, is an Assistant Scientist at the University of WisconsinMadison's Applied Population Laboratory. Dr. Jones specializes in innovative methods and measurement approaches in spatial and environmental demography. Her research centers on understanding how social patterning of space, including racial and economic segregation, produces and reproduces health disparities.

Nicole Kravitz-Wirtz is a Postdoctoral Fellow in the Population Studies Center at the University of Michigan. Her research focuses on racial-spatial stratification and the ways in which inequalities in exposure to household and neighborhood resources, hazards, and opportunity structures influence inequalities in health and well-being over the life course and across generations.

Jennifer Lai is a PhD candidate in the Department of Sociology at Michigan State University. Her research interests include studying the process of scientific knowledge production in the context of water governance, and water access in the United States and in Palestine. Lai holds a BS in agricultural and biological engineering from Purdue University, and calls St. Paul, Minnesota her hometown. 
Toby C. Lewis is Assistant Professor in the Departments of Pediatrics and Communicable Diseases and Environmental Health Sciences, University of Michigan, Ann Arbor. She completed an MD degree from Cornell University and MPH in Epidemiology from the University of Washington. Lewis is a practicing pediatrician whose research interests focus on the role of air pollution exposures in childhood asthma, and an established scholar in the use of community-based participatory research approaches to design and evaluate interventions designed to reduce asthma morbidity, with a particular focus on children living in low income urban communities.

Ricardo de Majo is a Database Analyst with the Department of Health Behavior and Health Education, University of Michigan School of Public Health, Ann Arbor. He completed a BS degree in Electrical Engineering with the Universidad Nacional de Tucuman in Argentina. de Majo's areas of expertise include database management, electronic survey research programming, geographic information systems, and mapping.

Graciela B. Mentz is Senior Statistician in the Department of Health Behavior and Health Education with the University of Michigan School of Public Health. Mentz received her MS in Statistics from the Universidad Nacional de Tucuman in Argentina and her PhD in Statistics from the University of Michigan. Her expertise in statistical analysis includes analysis from longitudinal studies using Generalized Additive Linear Mixed Models, and various, weighted linear and non-linear multivariate methods.

Orrianne Morrison is a native of Atlanta, Georgia. She received a BS in Biology in 2012 from Spelman College. While attending Spelman, she was awarded a Social Justice Fellowship during which she strengthened her understanding of complex social issues and the approaches used to address injustice. After serving as a middle grades educator for two years, Orrianne continued her education at Georgetown University, earning a Master's of Physiology and Biophysics in August of 2016. She is interested in the impacts of built environment and education on lifestyle and health in urban communities, and the use of complementary and integrative medicine in cancer. She is currently assisting in HIV research at the Food and Drug Administration and plans to continue her education afterwards.

Julius Moss received his bachelor's degree in Environmental Economics and Policy from Michigan State University in 2014. During the Academic year of 2013-2014, he was a research assistant to Professor Gasteyer, focusing on updating and furthering Professor Gasteyer's research on issues of water access in United States during the twenty-first century. He was also a teaching assistant in the computer science department at Michigan State from 2012-2014. He plans to continue his studies on water issues by pursing his Juris Doctorate in Environmental Law.

Michael Warren Murphy is a PhD candidate in the Department of Sociology at Brown University. His work is primarily situated at the intersections of race/racialization and environment/nonhuman nature. He is particularly interested in the ways in which socially constructed difference (race, class, gender, etc.) influences how human individuals and collectives relate to their environments, land, and nonhuman nature. Michael's MA thesis examined the mechanisms of primitive accumulation and land dispossession amongst the Narragansett Indians, and the inequality it produced, in the context of British settler colonialism and later state formation. His dissertation analyzes slavery and dispossession, in colonial Rhode Island, as dual processes that patterned human relations to the environs based on racialized understandings of African 
slaves and indigenous Americans. He received his BA in Sociology from the University of San Diego in 2012, and his MA in Sociology from Brown University in 2014.

Carla O'Connor is Professor of Education and an Arthur F. Thurnau Professor at the University of Michigan. She received an MA and PhD in Education from the University of Chicago and a BA in English from Wesleyan University. A sociologist of education, she has expertise in the areas of African American achievement, cultural studies, urban education, and ethnographic methods. Her work includes examinations of how Black identity is differentially constructed across multiple contexts and influences educational outcomes; how Black people's perceptions of opportunity vary within and across social space and shape academic orientation; how Black educational resilience and vulnerability is structured by social, institutional, and historical forces; and how the organization and culture of schools influence students' social and academic identities and outcomes. Her work has been published in the American Educational Research Fournal, Educational Researcher, Sociology of Education, Review of Research in Education, Teaching and Teacher Education, and Ethnic and Racial Studies. She co-edited (with Erin McNamara Horvat) the book, Beyond Acting White: Reframing the Debate on Black Student Achievement and has contributed to multiple handbooks and edited volumes that contend with issues of educational inequality and access. She is a PI for the NSF sponsored Center for the Study of Black Youth in Context.

Lisa Sun-Hee Park is Professor and Chair of Asian American Studies with affiliations in Sociology and Feminist Studies at the University of California, Santa Barbara. She received her $\mathrm{PhD}$ in Sociology at Northwestern University. Park's interdisciplinary research focuses on the politics of migration, race, gender, and social policy. She is currently researching health care access for low-income uninsured immigrants after passage of the Affordable Care Act. Her most recent books include: Entitle to Nothing: The Struggles for Immigrant Health Care in the Age of Welfare Reform (NYU 2011) and The Slums of Aspen: Immigrants vs. the Environment in America's Eden (co-authored with David N. Pellow, NYU 2011), which received the Outstanding Book Award from the American Sociological Association's Environment and Technology Section in 2014.

David N. Pellow is the Dehlsen Chair of Environmental Studies and Director of the Global Environmental Justice Project at the University of California, Santa Barbara. His teaching and research focus on environmental and ecological justice in the United States. and globally. His books include: Total Liberation: The Power and Promise of Animal Rights and the Radical Earth Movement, The Slums of Aspen: Immigrants vs. the Environment in America's Eden (with Lisa Sun-Hee Park), Resisting Global Toxics: Transnational Movements for Environmental Justice; and Garbage Wars: The Struggle for Environmental fustice in Chicago. He works with numerous organizations focused on improving the living and working environments for people of color and other marginalized communities.

Apollonya Maria Porcelli is a PhD candidate in the Sociology Department at Brown University. Her research examines the historical transformation of the Peruvian anchovy fishing industry from a point of collapse to one marked as the paragon of sustainability by exploring the intersections of political economy, science, and culture. She holds a BS in Natural Resources from Cornell University and an MS in Ecology and Evolutionary Biology (EEB) from Brown University. Her previous research has included focus on social capital in New England commercial fisheries and racialized fishing practices amongst Miskito Indian and Garifuna communities along 
Nicaragua's Caribbean coast. Prior to beginning graduate school, she worked as an assistant teacher for at-risk students in Cambridge, MA teaching construction and high school math and science.

Rashawn Ray is Associate Professor of Sociology at the University of Maryland, College Park. Ray obtained a PhD in Sociology from Indiana University in 2010. From 2010-2012 he was a Robert Wood Johnson Foundation Health Policy Research Scholar at the University of California, Berkeley/UCSF. Ray's research addresses the mechanisms that manufacture and maintain racial and social inequality. His work also speaks to ways that inequality may be attenuated through racial uplift activism and social policy. Ray was selected as one of " 40 Under 40, Prince George's County" in 2014 and has been awarded mentorship and teaching awards from the Philip Merrill Presidential Scholars Program, Ronald E. McNair Post-Baccalaureate Program, the University of Maryland, and Indiana University. Currently, he serves on the editorial boards for Sociology of Race and Ethnicity and Social Psychology Quarterly as well as on the American Sociological Association Committee on the Status of Racial and Ethnic Minorities in Sociology.

Natalie Sampson is Assistant Professor in the Department of Health and Human Services, University of Michigan-Dearborn Campus. She received a MPH from Portland State University, and her PhD in Health Behavior and Health Education from the University of Michigan. Sampson is expert in the use of community based participatory research approaches in addressing environmental health issues, including exposure to air pollutants, community activism to influence land use decisions, climate change, and environmental justice.

Robert J. Sampson is the Henry Ford II Professor of the Social Sciences at Harvard University. He is a member of the U.S. National Academy of Sciences and a Fellow of the American Academy of Arts and Sciences. Sampson is the author of three awardwinning books and numerous journal articles on social inequality, crime, disorder, the life course, neighborhood effects, immigration, civic engagement, ecometrics, and the social structure of the city. His most recent book is Great American City: Chicago and the Enduring Neighborbood Effect.

Victoria Sass is a doctoral student in Sociology at the University of Washington. Her research focuses on environmental inequality, racial/ethnic stratification, residential mobility, and health. She is interested in the ways environmental context impacts individuals' health outcomes and broader life chances.

Amy J. Schulz is Professor in the Department of Health Behavior and Health Education, University of Michigan School of Public Health, Ann Arbor. She is Principal Investigator or Co-Principal Investigator for a number of federally funded, community based participatory research partnerships focused on social and physical environmental contributions to health inequities, including the Healthy Environments Partnership (www.hep.detroit.com) and Community Action to Promote Healthy Environments (http://caphedetroit.sph.umich.edu/). Schulz received a MPH and a PhD in sociology from the University of Michigan. She has received numerous awards recognizing her contributions to public health, including the Harold R. Johnson Diversity Service Award and the School of Public Health Excellence in Research Award.

David T. Takeuchi is Professor and Dorothy Book Scholar in the School of Social Work and an affiliate faculty in the Department of Sociology at Boston College. He is 
a sociologist with a focus on the social, structural, environmental, and cultural contexts that are associated with different health outcomes, especially among racial and ethnic minorities. He is an elected member of the Sociological Research Association and the American Academy of Social Work and Social Welfare. He recently received the American Sociological Association Leonard Pearlin Award for Distinguished Study to the Sociological Study of Mental Health. He currently serves as the Secretary of the American Sociological Association.

Samantha Teixeira is Assistant Professor at the Boston College School of Social Work. She holds a PhD in social work and her current research focuses on how neighborhood environmental conditions affect youth and how youth can be engaged in creating solutions to environmental problems in their communities. She has published on the topics of place-based community interventions that address neighborhood environmental disparities, youth-led participatory research, and environmental justice. Her scholarship is shaped by her practice experience in child welfare, community organizing and development, and local government agencies. Teixeira's research has garnered several prestigious awards including the Marie Weil Award for the best article in the Fournal of Community Practice (2013-2014) and the Society for Social Work and Research Outstanding Dissertation Award (2014-2015).

Yonette F. Thomas is science advisor for urban health to the New York Academy of Medicine, a member of the International Society for Urban Health board, and a senior research advisor to the Association of American Geographers. She is founding Board Member and Vice President of the Interdisciplinary Association for Population Health Science (IAPHS). Previously she served as the chief of the Epidemiology Research Branch and program director for the social epidemiology program at the National Institute on Drug Abuse. Her research focuses on the social epidemiology of drug abuse and HIV/AIDS and the link with geography, including edited volumes: Geography and Drug Addiction; Crime, HIV, and Health: Intersections of Criminal fustice and Public Health Concerns; Trajectories of Drug Use among Minority Youth.

Brittany Tucker is a PhD student in Sociology at Michigan State University and a law candidate at Michigan State College of Law. Her research interests include the experiences of African American men situated in the Friends of the Court, and her pre-dissertation work focuses on drivers and consequences behind Multiple Partner Fertility. Tucker holds a BA in sociology and humanities pre-law from Michigan State University, and she hails from Detroit, Michigan.

Emily Walton is Assistant Professor at Dartmouth College. As the U.S. population continues to be shaped by immigration in the twenty-first century, her research aims to add complexity to the way scholars and policymakers understand the meanings of race and place. Her early work investigated co-ethnic neighborhood concentration, focusing on resilience and providing insight into factors that can promote health and well-being in disadvantaged communities. More recently, she has turned her attention toward understanding social interactions in multiethnic communities, asking how individuals with different backgrounds and identities may come together in transformative interaction.

Melanie Ward is a doctoral student in the Department of Health Behavior and Health Education, University of Michigan School of Public Health, Ann Arbor. Ward completed a bachelor's degree in Sociology and a master's degree in Health Management 
and Policy both from the University of Michigan. Her research interests include research-to-practice translation; specifically, using principles and methods from complex systems science to guide the design, implementation, and evaluation of public health interventions, policies, and community change efforts. She is a lifelong resident of the Detroit metropolitan area.

Donele Wilkins is Founder and CEO of Green Door Initiative, Detroit, focused on training for employment in green industries, youth development, civic engagement, and public policy consulting. She is widely recognized nationally for her leadership and expertise in environmental justice, and a sought-after consultant and speaker on environmental justice, environmental policy, and civic engagement in environmental decision making. Prior to founding the Green Door Initiative, Wilkins founded and directed Detroiters Working for Environmental Justice, a pioneering environmental justice organization, for over fourteen years.

Alix S. Winter is a PhD candidate in Sociology and Social Policy and a Doctoral Fellow in the Multidisciplinary Program in Inequality and Social Policy at Harvard University. Her research interests are in the areas of inequality, race and ethnicity, criminal justice, and the social determinants of health. Winter's research on how judges make sense of and address racial disparities in the criminal justice system was recently published in Criminology. 